\title{
Differing effect of systemic anti psoriasis therapies on platelet physiology - a case report and review of literature
}

\author{
Batya B Davidovici, Mary M Sullivan-Whalen, Patricia Gilleaudeau and James G Krueger*
}

\begin{abstract}
Background: Psoriasis is a common, chronic relapsing inflammatory skin disease. Lately, there is increasing evidence that psoriasis is more than "skin deep". Epidemiological studies showed that severe psoriasis might have also important systemic manifestations such as metabolic deregulations, cardiovascular disease (CVD) and increased mortality. Moreover, recently psoriasis patients were found to have platelet hyperactivity.

Case Presentation: This is a case report and review of the literature. We present a patient with long standing severe psoriasis vulgaris with marked thrombocytosis. His thrombocytosis did not correlate with disease severity but rather with the different treatments that he was exposed to, subsiding only during treatment with anti Tumor Necrosis Factor (TNF)- agents. A literature review revealed that in rheumatoid arthritis, another systemic inflammatory disease; interleukin (IL)-6 might be implicated in causing thrombocytosis.

Conclusion: This unique case report illustrates that different systemic treatments for psoriasis might have implications beyond the care of skin lesions. This insight is especially important in psoriasis patients in view of their deranged hemostatic balance toward a prothrombotic state, which might increase the risk of thrombosis and CVD. Therefore, further studies analyzing the effect of different drugs on platelets physiology are warranted.
\end{abstract}

\section{Background}

Psoriasis is a chronic relapsing prevalent disease affecting $2-4 \%$ of the world's population [1-3]. Severe psoriasis is a disabling disease affecting the physical and emotional well-being of patients, and its effect on quality of life is similar to that seen with other major medical diseases such as diabetes, rheumatoid arthritis, and cancer $[4,5]$.

Moreover, it is increasingly being recognized that in patients with severe or long-lasting disease, psoriasis is not merely a skin disease but is probably associated with other co-morbidities. Recently, studies based on large cohorts showed that severe psoriasis was association with metabolic derangements [6] and increased mortality [7]. Cardio-vascular diseases (CVD) were found to be the most common cause of death $[8,9]$. These data emphasize that the increased risk for occlusive vascular events in patients with severe psoriasis can be attributed not only

* Correspondence: kruegej@rockefeller.edu

1 Laboratory for Investigative Dermatology, The Rockefeller University, New York, NY, USA

Full list of author information is available at the end of the article to metabolic dysregulation, traditional lifestyle risk factors such as obesity, smoking or alcohol which have been also reported in these patients [10], but probably also to an independent risk directly resulting from the duration and severity of psoriatic inflammation.

We report a patient with long-standing severe psoriasis vulgaris with persistent reactive thrombocytosis that remitted only under anti TNF- therapy.

Recent data suggest that the hemostatic balance is deranged toward a prothrombotic state in psoriasis patients, which might be sustained by platelet hyperactivity, therefore this case pose a therapeutic dilemma concerning the need to treat reactive thrombocytosis in severe psoriasis patients.

\section{Case Presentation}

In November 2006, a 36 years old male presented with severe plaque type psoriasis, to our hospital clinic. He has had psoriasis for the last 13 years; first it was localized to the scalp and periodically spread to other small areas of his body so he could control his disease with topical ther- 
apy. However, for the last six years the disease spread and covered the majority of his integument. He denied prior history of psoriatic arthritis. He had a positive family history of psoriasis, which affected his father, sister and paternal grandmother, but they all had a milder disease. His past treatments included various topical agents and several years ago he had a course of UVB with significant improvement, however he could not resume phototherapy because he lost his health insurance. Otherwise his past medical history was unremarkable. He had no known drug allergies and did not smoke. His current medications included over the counter iron pills. He denied any other systemic medications.

Examination revealed severely erythematous scaly, excoriated thick plaques involving approximately $80 \%$ of his body surface area, and pitting of his nails. The rest of his physical examination was unremarkable. After completion of the screening tests which were within normal limits except from mild normocytic anemia (HGB $=12.0$ $\mathrm{gr} / \mathrm{d})$ and elevated platelets count $\left(470 \times 10^{3} / \mathrm{mc}\right.$, normal range $180-400 \times 10^{3} / \mathrm{mc}$ ) and receiving informed consent he was treated with efalizumab (Raptiva) $0.7 \mathrm{mg} / \mathrm{kg} \mathrm{SC}$ once weekly and subsequently $1 \mathrm{mg} / \mathrm{kg}$ as per label. Under treatment his skin condition has gradually improved. However, after 3 months of treatment he had started to complain of arthralgia first involving his right ankle and latter on extending to 2 fingers in both hands and eventually to his left ankle. Treatment with Ibouprofen $600 \mathrm{mg}$ twice daily did not relieve his pain. X-ray analysis confirmed the diagnosis of psoriatic arthritis therefore treatment with Efalizumab was interrupted after 9 months. In addition during the 9 months of efalizumab therapy his platelets count rose substantially (Figure 1). Then, etanercept (Enbrel) $50 \mathrm{mg}$ twice weekly was started. After an initial flare of his skin condition, which was expected after cessation of efalizumab, a significant improvement of both his skin and joints ensued. Interestingly during the sixteen months of etanercept treatment his platelets count returned to normal. But unfortunately due to health insurance coverage problems he had to stop etanercept and consequently his skin conditioned dramatically deteriorated and resembled his baseline condition when he first reported to our clinic. Therefore cyclosporine (Neoral) $200 \mathrm{mg}$ twice daily was introduced for approximately 2 months till he received his insurance approval for adalimumab (Humira) and again his skin and arthritis gradually improved. His platelets count rose while being off etanercept and even when he was treated with cyclosporine and his skin condition started to improve his platelets counts remained persistently high and only after adalimumab was started they returned to normal values.

\section{Results and Discussion}

Thrombocytosis is classified as either primary (familial and clonal) or secondary. Unlike essential thrombocyto- sis, which is usually a form of myeloproliferative disease, reactive thrombocytosis is an exaggerated physiologic response to a primary stimulus thus it may accompany infections, iron deficiency anemia, hemorrhage, hyposplenism or chronic inflammatory diseases. Among other inflammatory diseases thrombocytosis was reported as a complication of inflammatory bowel diseases (IBD) $[11,12]$ and rheumatoid arthritis (RA). However, in psoriasis, which is also a chronic inflammatory disease there is only one previous report of reactive thrombocytosis. That report included two patients with psoriasis who had episodes of fever, arthritis, and general fatigue [13]. Their symptoms seemed to be associated with increases in serum levels of platelet counts, IL-6, and elevated serum titers of C-reactive protein (CRP), which paralleled the severity of clinical symptoms. Platelet count has also been shown to correlate with disease activity in IBD. Similarly thrombocytosis usually occurs during the active clinical stages of RA and it was demonstrated to parallel disease activity [14].

Our case is unique since he had mildly elevated platelet counts at baseline, which continued to raise despite the improvement of his skin condition a result of efaluzimab treatment. This is specifically interesting since efalizumab, which is a humanized anti-CD11a monoclonal antibody (IgG1) that acts by blocking the interaction of lymphocyte function-associated antigen 1 with intracellular adhesion molecule 1, was described to cause an autoimmune thrombocytopenia in $0.3 \%$ of cases, based on data of the tolerance of 3,291 efaluzimab treated patients. There is only one other published case of a psoriasis patient that developed thrombocytosis while being treated with efalizumab [15]. However in that case the thrombocytosis diminished gradually, upon stopping the efalizumab, and after 9 weeks, returned to normal values. The onset mechanism of this phenomenon does not suggest an explanation. However, it is known that the activated platelets express CD11a [16]. In our patient, the thrombocytosis was probably not an adverse reaction to efaluzimab as it continued even after the drug was interrupted.

Efaluzimab is also known to infrequently cause new onset or recurrent severe arthritis events, including psoriatic arthritis. And indeed while on efaluzimab treatment our patient experienced severe arthritis, which was later on diagnosed to be psoriatic arthritis, and therefore this treatment was interrupted. The only case report of reactive thrombocytosis in psoriasis was in two patients who had also arthritis [13]. Therefore it is also possible that the development of psoriatic arthritis could have contributed to his rising platelet counts.

In our patient, the platelet count continued to rise while cyclosporine was administered with gradual improvement of his skin condition although, cyclosporine is reported to cause thrombocytopenia in $2 \%$ or less of the 


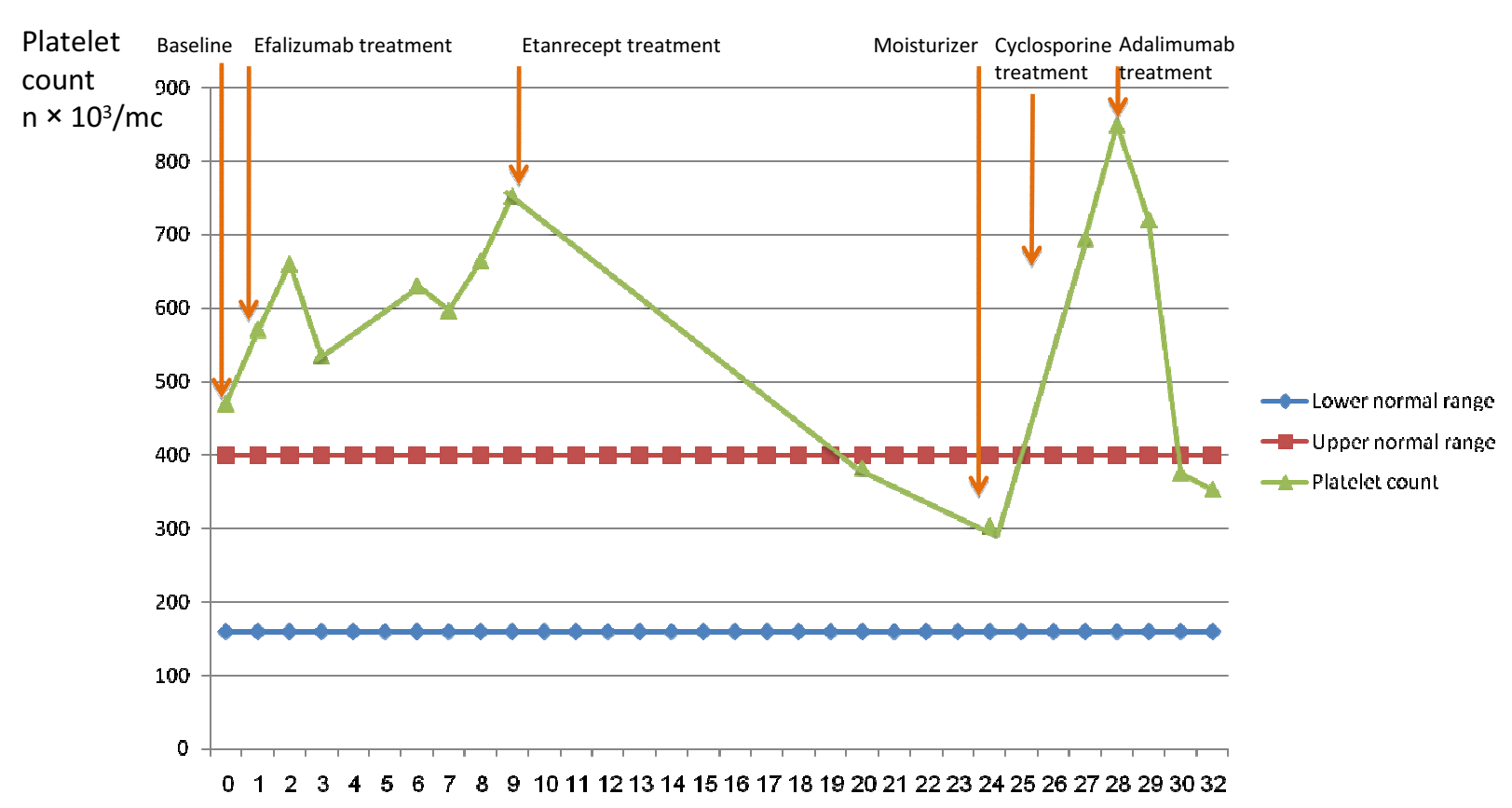

Time (months)

Figure 1 Platelet counts during different anti psoriatic therapies in our patient.

treated patients and there is no other case report of thrombocytosis during cyclosporine treatment.

In our patient platelet counts return to normal only during the periods that he was treated with anti TNFs (etanercept, adalimumab) and did not correlate with disease activity (Figure 1). The normalization of thrombocytosis was previously reported following treatment of RA patients with anti TNFs [17]. Attempts have been made to explain increments in the platelet counts. Some authors postulated that the symptoms and abnormal laboratory findings in these patients might be related to increased serum levels of IL-6, since IL-6 is a multipotential cytokine with B-cell activating, T-cell activating, and thrombocytopoietic functions [13]. It was previously demonstrated that thrombocytosis secondary to the inflammation of RA can be modulated by proinflammatory megakaryocyte-related interleukins, IL-6, IL-1b and IL-4 $[18,19]$. In patients with active inflammatory bowel disease, Heits et al. [20], disclosed that the levels of thrombopoietin (TPO), which is the main regulator hormone of platelet production, were significantly increased in association with thrombocytosis and elevated IL-6 levels. Furthermore, it was demonstrated that IL-6-induced thrombocytosis in mice is accompanied by enhanced hepatic TPO mRNA expression and elevated TPO plasma levels [20]. In addition administration of IL-6 to cancer patients resulted in a corresponding increase in
TPO levels [20]. Similarly others have also identified positive correlations between platelet count and IL-6 and between TPO and IL-6 [21]. Yet in their study they confirmed that TPO acts as an acute phase protein but excluded the possibility that it is uniquely responsible for thrombocytosis of inflammatory disorders. This might recognize in IL-6 a credible candidate as a cooperating factor.

Interestingly, in a relatively big study of 219 patients with psoriasis and psoriatic arthritis, IL-6 was significantly higher in patients with psoriasis and inflammatory joint disease compared with patients having psoriasis of the skin [22].

It should be remembered that Il- 6 has also a central role in the pathogenesis of psoriasis as $\mathrm{T}$ memory/effector cells (Tmem/eff) isolated from psoriatic patients are chronically activated and poorly suppressed by regulatory T cells (Treg). IL-6, which signals through Stat3, allows escape of Tmem/eff cells from Treg-mediated suppression in a murine system. In a recent study, Goodman et al [23], showed that IL-6 is elevated and most highly expressed by CD31(+) endothelial cells and CD11c(+) dermal dendritic cells (DCs) in lesional psoriatic skin. They found that IL-6, but not other Stat3-activating cytokines, was necessary and sufficient to reverse human $\mathrm{T}$ cell suppression by Treg in an in vitro model using activated DCs as a source of IL-6. They identified cells within 
lesional tissue that co-express CD3, IL-17, and IL-6, indicating that Th17 cells are present in vivo within the psoriatic Tmem/eff population and contribute to IL-6mediated resistance to Treg suppression.

Cyclosporine is a calcineurin inhibitor that was reported to increase IL- 6 production and IL- 6 mRNA expression [24]. In fact this is suspected to be the mechanism by which cyclosporine induces renal damage and that the use of an IL-6-neutralizing antibody may be useful in reducing cyclosporine-induced renal damage [25]. Moreover cyclosporine-upregulated IL-6 gene expression in vivo, may explain in part the molecular mechanisms responsible for cyclosporine -induced gingival overgrowth [26]. In a previous study cyclosporine induced IL$1 \beta$ expression in circulatory leukocytes and this might be sufficient to induce IL-6 production in some tissues [27]. This is also probably the reason of the sustained and even increase in platelet counts seen in our patient during cyclosporine treatment.

Anti TNF- however down-regulates the production of IL-1, IL-6, IL-8, and GM-CSF $[28,29]$. The reductions in circulating IL-6 in anti TNF-treated RA patients were reaching significance from the first day of treatment [30]. Therefore anti TNFs might normalize platelet counts through the reduction of circulating IL-6 levels.

Furthermore, increased platelet activation and aggregation have been demonstrated to be the features of IBD and has been proposed to contribute to the pathogenesis of mucosal inflammation seen in the condition [31]. In psoriasis patients, evidence for an in vivo platelet activation, which could contribute to the development of thrombotic events, has also been established [32]. Spontaneous platelet hyperaggregability, mean platelet volume, plasma levels of $\beta$-thromboglobulin and platelet factor 4, which are markers of platelet activation, were found to be significantly higher in psoriasis patients compared with that in controls. Interestingly, these markers, as well as platelet aggregability were significantly reduced after psoriasis had cleared [33]. Moreover, platelet regeneration time, measured as malondialdehyde (MDA) recovery after aspirin ingestion, was significantly shorter in psoriasis patients [34,35]. Finally, P-selectin expression by platelets was also increased in psoriasis patients, showing a direct correlation with disease severity [36]. Simultaneously, activated platelets may play a role in psoriasis pathogenesis by favoring leukocyte rolling in the skin microvasculature [36] and platelet derived 12hydroxyeicosatetraenoic acid may increase keratinocyte DNA synthesis [37].

Finally, there is a therapeutic dilemma because reactive thrombocytosis (even at this level) is often not treated, as the chance of thrombosis is very rare. However, it is important to bear in mind that severe psoriasis itself is a risk factor for metabolic derangements [6], cardiovascu- lar diseases and thrombosis [7-9] probably as a result of the chronic inflammatory nature of the condition. Thus, some hematologists tend to give an anti-platelet agent or low molecular weight heparin in these circumstances especially if there is another coexisting risk factor for thrombosis [38]. Until more is known about the pathophysiology of the increased risk for CVD in psoriasis patients, such a therapeutic approach might be recommended.

\section{Conclusion}

Different anti psoriasis therapies might have different effects on platelet physiology. In view of the increased risk of thrombosis and CVD in severe psoriasis patients further studies analyzing the effect of different drugs on platelets physiology are warranted.

\section{Competing interests}

The authors declare that they have no competing interests.

\section{Authors' contributions}

All persons who meet authorship criteria are listed as authors: BBD participated in the design, analysis and wrote the manuscript. MMSW and PG helped with the acquisition of data and manuscript revision with the acquisition of data and manuscript revision. JGK participated in the design, analysis and revised the manuscript. All authors have given final approval of the version to be published

\section{Author Details}

Laboratory for Investigative Dermatology, The Rockefeller University, New York, NY, USA

Received: 2 September 2009 Accepted: 31 March 2010

Published: 31 March 2010

\section{References}

1. Langley RG, Krueger GG, Griffiths CE: Psoriasis: epidemiology, clinical features, and quality of life. Ann Rheum Dis 2005, 64(Suppl 2):ii18-23. discussion ii24-15.

2. Schon MP, Boehncke WH: Psoriasis. N Engl J Med 2005, 352(18):1899-1912.

3. Koo J: Population-based epidemiologic study of psoriasis with emphasis on quality of life assessment. Dermatol Clin 1996, 14(3):485-496.

4. Christophers E: Psoriasis--epidemiology and clinical spectrum. Clin Exp Dermatol 2001, 26(4):314-320.

5. Rapp SR, Feldman SR, Exum ML, Fleischer AB Jr, Reboussin DM: Psoriasis causes as much disability as other major medical diseases. J Am Acad Dermatol 1999, 41(3 Pt 1):401-407.

6. Henseler T, Christophers E: Disease concomitance in psoriasis. J Am Acad Dermatol 1995, 32(6):982-986.

7. Gelfand JM, Troxel AB, Lewis JD, Kurd SK, Shin DB, Wang X, Margolis DJ, Strom BL: The risk of mortality in patients with psoriasis: results from a population-based study. Arch Dermatol 2007, 143(12):1493-1499.

8. McDonald CJ, Calabresi P: Psoriasis and occlusive vascular disease. $\mathrm{Br} J$ Dermatol 1978, 99(5):469-475.

9. Mallbris L, Akre O, Granath F, Yin L, Lindelof B, Ekbom A, Stahle-Backdahl M: Increased risk for cardiovascular mortality in psoriasis inpatients but not in outpatients. Eur J Epidemiol 2004, 19(3):225-230.

10. Naldi L, Chatenoud L, Linder D, Belloni Fortina A, Peserico A, Virgili AR, Bruni PL, Ingordo V, Lo Scocco G, Solaroli C, Schena D, Barba A, Di Landro A, Pezzarossa E, Arcangeli F, Gianni C, Betti R, Carli P, Farris A, Barabino GF, La Vecchia C: Cigarette smoking, body mass index, and stressful life events as risk factors for psoriasis: results from an Italian case-control study. J Invest Dermatol 2005, 125(1):61-67. 
11. Collins CE, Rampton DS: Review article: platelets in inflammatory bowel disease--pathogenetic role and therapeutic implications. Aliment Pharmacol Ther 1997, 11(2):237-247.

12. Harries AD, Beeching NJ, Rogerson SJ, Nye FJ: The platelet count as a simple measure to distinguish inflammatory bowel disease from infective diarrhoea. J Infect 1991, 22(3):247-250.

13. Yasumoto S, Imayama S, Hori Y: Increased serum level of interleukin-6 in patients with psoriatic arthritis and thrombocytosis. J Dermatol 1995, 22(10):718-722.

14. Ertenli I, Kiraz S, Ozturk MA, Haznedaroglu I, Celik I, Calguneri M: Pathologic thrombopoiesis of rheumatoid arthritis. Rheumatol Int 2003, 23(2):49-60

15. Firmin D, Roguedas AM, Lemasson G, Abgrall JF, Misery L: Eczematous dermatosis and thrombocytosis induced by efalizumab: two new side effects. Dermatology 2008, 217(3):203-206

16. Philippeaux MM, Vesin C, Tacchini-Cottier F, Piguet PF: Activated human platelets express beta2 integrin. Eur J Haematol 1996, 56(3):130-137.

17. Elliott MJ, Maini RN, Feldmann M, Kalden JR, Antoni C, Smolen JS, Leeb B, Breedveld FC, Macfarlane JD, Bijl H, Woody JN: Randomised double-blind comparison of chimeric monoclonal antibody to tumour necrosis factor alpha (CA2) versus placebo in rheumatoid arthritis. Lancet 1994, 344(8930):1105-1110.

18. Haznedaroglu IC, Ertenli I, Ozcebe Ol, Kiraz S, Ozdemir O, Sayinalp NM, Dundar SV, Calguneri M, Kirazli S: Megakaryocyte-related interleukins in reactive thrombocytosis versus autonomous thrombocythemia. Acta Haematol 1996, 95(2):107-111

19. Ertenli I, Haznedaroglu IC, Kiraz S, Celik I, Calguneri M, Kirazhi S: Cytokines affecting megakaryocytopoiesis in rheumatoid arthritis with thrombocytosis. Rheumatol Int 1996, 16(1):5-8.

20. Heits F, Stahl M, Ludwig D, Stange EF, Jelkmann W: Elevated serum thrombopoietin and interleukin- 6 concentrations in thrombocytosis associated with inflammatory bowel disease. J Interferon Cytokine Res 1999, 19(7):757-760.

21. Ceresa IF, Noris P, Ambaglio C, Pecci A, Balduini CL: Thrombopoietin is not uniquely responsible for thrombocytosis in inflammatory disorders. Platelets 2007, 18(8):579-582.

22. Alenius GM, Eriksson C, Rantapaa Dahlqvist S: Interleukin-6 and soluble interleukin-2 receptor alpha-markers of inflammation in patients with psoriatic arthritis? Clin Exp Rheumatol 2009, 27(1):120-123.

23. Goodman WA, Levine AD, Massari JV, Sugiyama H, McCormick TS, Cooper KD: IL- 6 signaling in psoriasis prevents immune suppression by regulatory T cells. JImmunol 2009, 183(5):3170-3176.

24. Storogenko M, Pech-Amsellem MA, Kerdine S, Rousselet F, Pallardy M: Cyclosporin-A inhibits human endothelial cells proliferation through interleukin-6-dependent mechanisms. Life Sci 1997, 60(17):1487-1496.

25. LaSpina M, Tripathi S, Gatto LA, Bruch D, Maier KG, Kittur DS: An interleukin-6-neutralizing antibody prevents cyclosporine-induced nephrotoxicity in mice. J Surg Res 2008, 148(2):121-125.

26. Williamson MS, Miller EK, Plemons J, Rees T, lacopino AM: Cyclosporine A upregulates interleukin- 6 gene expression in human gingiva: possible mechanism for gingival overgrowth. J Periodontol 1994, 65(10):895-903.

27. Haider AS, Lowes MA, Suarez-Farinas M, Zaba LC, Cardinale I, Khatcherian A, Novitskaya I, Wittkowski KM, Krueger JG: Identification of cellular pathways of "type 1," Th17 T cells, and TNF- and inducible nitric oxide synthase-producing dendritic cells in autoimmune inflammation through pharmacogenomic study of cyclosporine A in psoriasis. $J$ Immunol 2008, 180(3):1913-1920.

28. Brennan FM, Chantry D, Jackson A, Maini R, Feldmann M: Inhibitory effect of TNF alpha antibodies on synovial cell interleukin-1 production in rheumatoid arthritis. Lancet 1989, 2(8657):244-247.

29. Haworth C, Brennan FM, Chantry D, Turner M, Maini RN, Feldmann M: Expression of granulocyte-macrophage colony-stimulating factor in rheumatoid arthritis: regulation by tumor necrosis factor-alpha. Eur $J$ Immunol 1991, 21(10):2575-2579.

30. Charles P, Elliott MJ, Davis D, Potter A, Kalden JR, Antoni C, Breedveld FC, Smolen JS, Eberl G, deWoody K, Feldmann M, Maini RN: Regulation of cytokines, cytokine inhibitors, and acute-phase proteins following anti-TNF-alpha therapy in rheumatoid arthritis. J Immunol 1999, 163(3):1521-1528

31. Collins CE, Cahill MR, Newland AC, Rampton DS: Platelets circulate in an activated state in inflammatory bowel disease. Gastroenterology 1994 106(4):840-845
32. Kasperska-Zajac A, Brzoza Z, Rogala B: Platelet function in cutaneous diseases. Platelets 2008, 19(5):317-321

33. Hayashi S, Shimizu I, Miyauchi H, Watanabe S: Increased platelet aggregation in psoriasis. Acta Derm Venereo/ 1985, 65(3):258-262

34. Berrettini M, Parise P, Constantini V, Grasselli S, Nenci GG: Platelet activation in psoriasis. Thromb Haemost 1985, 53(2):195-197.

35. Tamagawa-Mineoka R, Katoh N, Ueda E, Masuda K, Kishimoto S: Elevated platelet activation in patients with atopic dermatitis and psoriasis: increased plasma levels of beta-thromboglobulin and platelet factor 4 . Allergol Int 2008, 57(4):391-396.

36. Ludwig RJ, Schultz JE, Boehncke WH, Podda M, Tandi C, Krombach F, Baatz $H$, Kaufmann R, von Andrian UH, Zollner TM: Activated, not resting, platelets increase leukocyte rolling in murine skin utilizing a distinct set of adhesion molecules. J Invest Dermatol 2004, 122(3):830-836.

37. Kragballe K, Fallon JD: Increased aggregation and arachidonic acid transformation by psoriatic platelets: evidence that platelet-derived 12-hydroxy-eicosatetraenoic acid increases keratinocyte DNA synthesis in vitro. Arch Dermatol Res 1986, 278(6):449-453.

38. Schafer Al: Thrombocytosis and thrombocythemia. Blood Rev 2001, 15(4):159-166

\section{Pre-publication history}

The pre-publication history for this paper can be accessed here: http://www.biomedcentral.com/1471-5945/10/2/prepub

doi: 10.1186/1471-5945-10-2

Cite this article as: Davidovici et al., Differing effect of systemic anti psoriasis therapies on platelet physiology - a case report and review of literature BMC Dermatology 2010, 10:2

\section{Submit your next manuscript to BioMed Central and take full advantage of:}

- Convenient online submission

- Thorough peer review

- No space constraints or color figure charges

- Immediate publication on acceptance

- Inclusion in PubMed, CAS, Scopus and Google Scholar

- Research which is freely available for redistribution
C BioMed Central 